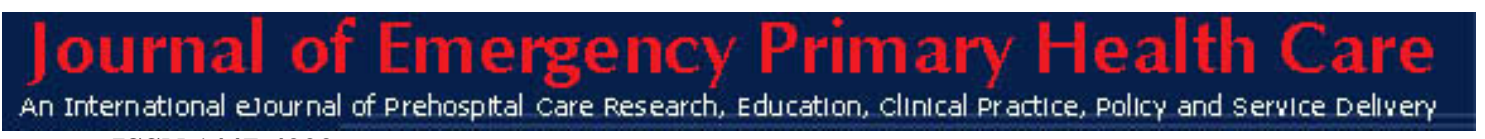

ISSN 1447-4999

STUDENT CONTRIBUTION

Article No. 990159

\title{
Paramedic clinical judgment of mental illness: Representations of official accounts
}

\author{
Ramon Z. Shaban BSc(Med) BN PGDipPH\&TM ADipAppSc(Amb) GCertInfecCon \\ MCHPrac(Hons) MEd RN \\ Research Centre for Clinical Practice Innovation \\ School of Nursing and Midwifery \\ Griffith University, Queensland, Australia
}

\begin{abstract}
This paper is the fourth in a series that heralds a study that examines paramedic accounts and constructs of judgment and decision-making (JDM) of mental health and mental illness. This paper will provide the results of one stage of this study in which a discourse-historical case study of paramedic JDM of mental health and mental illness using ethnographic and ethnomethodological research methods was conducted. Preliminary themes describing the ways in which paramedics officially account for their judgments of mental illness will be presented.
\end{abstract}

\section{Keywords}

ambulance officer; decision-making; judgment; mental illness; paramedic.

\section{Introduction}

In earlier papers, ${ }^{1,2}$ the warrant for research, literature review and theoretical framework for research into judgment and decision-making practices of paramedics in the context of mental health and mental illness were established. The aim of the overarching study was to examine paramedic JDM constructs and practices with respect to assessment of mental illness in the pre-hospital emergency care setting. Through investigation of paramedic practice, the study seeks to make known tacit and otherwise unavailable constructs and accounts of knowledge, judgment, and decision-making processes that underpin the performance of mental health assessment of patients in the emergency pre-hospital care setting. The study proposed to investigate the JDM experiences of paramedics in a comprehensive and innovative way, acknowledging and including perspectives from both classical and natural paradigms that are essential to the comprehensive understanding of JDM, discussed in earlier papers. ${ }^{3-5}$ Using these paradigms, the attempts to understand and document descriptive (how paramedics in ordinary contexts and situations do make judgments and decisions) and normative (how paramedics should make judgments and decisions) accounts of paramedic JDM with respect to mental health and mental illness. In doing so, the study then further aimed to explore prescriptive accounts of JDM (or how to make better judgments and decisions). It was considered essential to have an understanding and insight into how paramedics actually do make their judgments and decisions (in real contexts and ecologies), and how they should be making their judgments and decisions (in view of prevailing official accounts, standards, policies, and guidelines) before considering ways to improve their judgments or make them 
better. In doing so, the study attempts to understand what informed or influenced their judgments in this setting and context.

In this paper, we examined one element of the overall study - how paramedics are expected to officially account for their JDM with respect to mental illness in the emergency care setting. This component of the continuing study sought to explore how official accounts of paramedic JDM are represented and accounted for.

\section{Research Design, Methodology, and Data Collection}

The theoretical framework suggested by Shaban ${ }^{5}$ was used to guide the research design, data collection, and analysis of this component of the continuing study. The study used discoursehistorical case study as the primary methodology, applying ethnographic and discourse analytic techniques in data analysis.

The first data set incorporated the gathering and analysis of 'official, expected, or intended' accounts and standards of paramedic JDM of mental illness. This included the collection of a comprehensive array of material such as policies, procedures, clinical guidelines, pedagogical materials, standards, policies, and legislation. An extensive data set was obtained, culminating in the collection of a variety of documents including legislation, memoranda, letters, correspondence, clinical standards and guidelines, policy, procedures manuals, and pedagogical material over a historical period spanning 15 years. The corpus included a large volume of historical documentation such as current and superseded pedagogical material, policies, and procedures, including working drafts and consultation documents.

This material was then catalogued and examined. A first-pass ethnographic analysis of the two documents was conducted, including Membership Categorisation Analysis (MCA), Linguistic Analysis (LA), and Document and Policy Analysis (DPA) as described by Freebody ${ }^{6}$ and Silverman. ${ }^{7,8}$ Analysis of these documents illustrated an anomaly in official accounts as described by the original warrant for the research by Shaban. ${ }^{1}$ From this analysis, a series of questions were formulated for use in semi-structured interviews with key stakeholders of the research problem that on analysis will provide insight into the 'official responses' to prescriptive accounts and constructs. Of paramount interest at this stage in data collection was how paramedics might be expected account for their judgments considering the prevailing official standards and guidelines, and how the prevailing policies, or normative accounts (how judgments should be made and accounted for) mandate or are mandated by practice.

A historical-discourse perspective was used, to allow for a thick and dense description of the evolution of this phenomenon. Two key documents - the QAS Clinical Practice Manual and the Mental Health Act 2000 (Qld) — were used at interview to provide a focus for discussion as to what influence the policy has in mandating practice, or if indeed practice mandated an interpretation of the policy not represented in the official accounts. A total of six semistructured interviews were conducted, with a variety of key stakeholders, including a practicing advanced care paramedic, an two senior education officials (one manager and one educator), an ambulance operational manager, a union delegate, and an ambulance medical officer. Interviews were recorded on digital recorders, transcribed, and returned to interviewees for verification. Interview transcripts was analysed using a variety of discourse, ethnographic, and ethnomethodological methods outlined by Silverman, ${ }^{8}$ Freebody, ${ }^{6}$ and Baker[9]. These included Membership Categorisation Analysis (MCA), Discourse Linguistic Analysis (LA), and Conversation Analysis (CA). The complementarity of the research 
approaches and analytic methods will be examined in the continuing study. Ethics approval was obtained from the Commissioner and Medical Director, Queensland Ambulance Service, and Griffith University Human Research Ethics Committee.

\section{Preliminary Thematic Considerations}

A number of important preliminary themes have emerged from first-pass analysis of the data.

\section{Categories of the mentally ill}

The ways in which the mentally ill are categorised within the official accounts of the data correlate strongly with the existing related literature in allied health professions such as nursing $^{10,11}$ medicine $^{12}$ and the police. ${ }^{13-15}$

Interviewer: 'In the paramedic setting, how might psychiatric patients be viewed?'

Participant: '...I would have to say in my view most psychiatric patients I think would have been identified loosely under a dreadful term as 'mad people' and the police would have been called, I'd suggest...' (Excerpt from interview with participant 2 - senior ambulance manager)

The official accounts suggest that categories of mentally ill are most frequently identified as presenting with violent, suicidal, drug-induced, overdose, or overtly psychotic behaviour, and appear to dominate the official account of the experience base in the pre-hospital paramedic setting. The clinical category to which mental illness is assigned in clinical policies and procedures is that of 'psychiatric emergency'. What is unclear at this stage is how mental illness, wether or not it is classified as an emergency, is recognised, managed or represented in the field. Stereotyping of mental illness is pandemic and found across other health professions. $^{10}$ How paramedics themselves specifically categorise, recognise, represent, and manage mentally illness, or those they consider to be mentally ill, will be further investigated in this study.

\section{Role of the paramedic}

Preliminary data analysis suggests that the official account of the working role of the paramedic has changed rapidly over the last decade, which is consonant with movement with the pre-hospital and paramedic discipline nationally and internationally. For example, the standard of education has moved dramatically from non-standardised, non-accredited, inhouse vocational training to accredited vocational training and tertiary programs such as graduate diplomas and research higher degrees in just over 15 years.

Interviewer: 'Historically, what has been the role of the paramedic in the delivery of care?'

Participant: '...Ostensibly the various committees at that time had very, very little in the way of training. Even baseline first aid training, from my understanding, was extremely primitive...

Interviewer: 'And in 1991?'

Participant: 'There was a notion that they would try and increase the academic level-the Service would increase the academic level of the service and introduce the associated diploma... It took a few years after 199, for the single service notion. The introduction of the 
Associate Diploma, the bridging program, there was huge change at the front end of the business and the creation of a Commissioner position, at the creation of the single service had an extraordinary effect, I think, on the professionalism of the ambulance service and the concept in the mind of the ambulance officers of the job that they were actually going to do. As I said, from 1991 to the present day, there has been such a paradigm shift in terms of ambulance officers being seen as pre-hospital professionals treating as well as transporting patients, and you know, use the analogy that prior to 1991, an ambulance officer would arrive, hand some paper work to a nursing staff at a causality department and the paper work would often be thrown away. Now days we walk in with the elaborate ambulance report form and there is an expectation that the patient would have been assessed in a particular way, that a provisional diagnosis would have been made to guide the treatment, comprehensive handover given, and that record is filed with the patient's documentation and seen as a valuable adjunct if the person goes to orthopaedic surgery. You know, that sort of stuff. So just huge, huge changes...' (Excerpt from interview with participant 2 - senior ambulance manager)

This rapid change in the role of the paramedic has precipitated the introduction of additional skills, procedures, and training aimed to improve the pre-hospital management of a variety of medical conditions.

Interviewer: Do you see the role of the paramedics to include managing neuroses, depression, and anxiety-based conditions rather than just psychiatric emergencies, and if so, do we need another card [protocol]?

Participant: '...we get in the ambulance service as you know, we get a lot of calls to patients who are depressed, who are suffering from phobias, or neurosis of all sorts and they call the ambulance often as they have no other form of care, or they are feeling lonely, unwell or safe and if they want to get to a place of safety they don't have any mechanism to getting there, none of those patients are what you would term a psychiatric emergency at that point, unless they are going to self-harm, that may not be the case, they might be just feeling unsafe and want to go into care and we get called to those patients all the time, and I think... I think, sadly, those patients are still, not well understood, they are not treated appropriately by some ambulance services...'

Interviewer: Are there any specific reasons for that do you think?

Participant: '...I think the ambulance officers have insufficient training to understand how these people are presenting. There is a bit of a culture in ambulance which pushes us towards this urgency, lights and sirens, psychiatric emergency-that's an ambulance job, if it's a person just not feeling unwell then why couldn't they wait until tomorrow and go down to their local doctor. Well because to them it is a very acute situation and they need help and they're as needy as the child with the cut finger on the jam tin...' (Excerpt from interview with participant 1 - senior ambulance education official)

Traditionally, such skills and procedures have commonly anchored around conditions such as cardiac arrest, asthma, trauma, and endocrine emergencies such as hypoglycaemia. A common denominator of these conditions is that they are anchored in 'physical' where paramedic are able to recognise conditions using hypothetico-deduction processes. ${ }^{16}$ What is unclear at this preliminary stage is how official accounts of additional skills, education, and training have prepared the paramedic to meet with other non-explicit cases (such as those that 
do not necessarily require immediate time critical intervention) such as the broad sweep of mental illness. Further exploration is needed and will be conducted in the remainder of the study.

\section{Need for additional training, preparation, and clinical practice clarification}

A common theme across the official accounts is the reported need for greater education and training in mental illness and clinical judgment and decision-making, which is congruent with official accounts of mental illness in the majority of the health professions ${ }^{10,12,14}$ and across the community. ${ }^{17}$

Interviewer: 'Would it be fair to say that perhaps most of the experiences of ambulance officers are with psychotic patients or those with serious mental illness rather than say the neuroses or other less explicit conditions?'

Participant: 'My understanding at just looking at our AIMS data, is that mental illness and its manifestations which is so confused with other issues, like drugs, is becoming so prevalent and it is a real conundrum for our ambulance officers to be able to differentiate the cause of this disturbed and abnormal behaviour..'

Interviewer: 'If I asked you to summarise, do you think paramedics are well equipped to manage mental illness in pre-hospital context'.

Participant: 'Ambulance officers are not exposed to seriously mental ill patients all that frequently. We see a lot of sub-acute presentations of patients and we have little training in the area and basically we go out and treat the patients systematically, as we do with many things. So in answer to your question no I don't think we are well equipped...' (Excerpt from interview with participant 1 - senior ambulance education official)

Participants were asked to consider wether or not they were adequately prepared to manage mental illness in the emergency care setting.

Interviewer: 'If you were to summarise how well do you think paramedic are to assess and manage mental illness in their practice?'

Participant: 'Very poorly equipped, and I have to say there is a disinterest. I have to say there is a disinterest. Because there is a fear of mental stigma, because I don't need to bother, they can either call the police, treat them as dangerous, and they don't particularly want to know.' (Excerpt from interview with participant 5 - Ambulance counsellor)

Interviewer: 'In your experience how do you see that paramedic manage or handle mental illness? Are they well equipped to deal with it?'

Participant: 'As with most things in the job, some are, some aren't, and it gets down to individual things probably the interest the individuals has, the background experience in the service, and the educational models. So it is really an individual things on a whole I would probably say we are probably under equipped in so far as what we are doing under the Mental Health Act is putting us into a legal realm as such, as we are grabbing people under the Act, we may not do well if things actually went court.' (Excerpt of interview with participant 6 - union delegate) 


\section{Legislative, Policy and Clinical Practice Conflict}

There appears, on preliminary document analysis, conflict in the official accounts across legislation, policy, and practice. The two legislative instruments governing paramedic practice with respect to the mentally ill (particularly involuntary assessments), the Ambulance Service Act 1991 (Qld) (herein ASA) and the Mental Health Act 2000 (Qld) (herein MHA), appear to mandate practice and different ways, making their implementation problematic.

Interview: 'How would you characterise the preparedness of emergency service personnel to deal with their legislative requirements?'

Participant: '...I think both police and ambulance are in a very difficult position when the legalisation asks them to make value judgment calls when they are ill equipped to be able to comment on, and so that has always been an issue for me.' (Excerpt of interview with participant 3 - senior ambulance manager)

The ASA mandates that paramedics may take any reasonable measure to protect individuals, whereas the MHA mandate the formulation of a 'belief' of mental illness to enable action and decisions. The third dimension of the official account, the Clinical Practice Manual, mandates that all patients who are categorised as a 'psychiatric emergency' be transported to definitive medical care.

Interviewer: 'So are ambulance officers more likely to use the Ambulance Service Act and not have to make that belief, and protect the patient, rather than use Mental Health Act and have to make a belief judgment and then invoke an order?'

Participant: 'If you can take a person to hospital under your powers under the Ambulance Service Act and the person is compliant, and is happy to stay in hospital and be assessed, why fill out an Emergency Examination Order?. Whereas, under the Mental Health Act, it is far more prescriptive in terms that you have to met all these criteria and you have to believe that the person is a mental illness and don't have any of the exclusions. You know, it puts an extraordinary number of almost impedients in the way of the paramedic, in saying take this person to hospital...' (Excerpt of interview with participant 2 - senior ambulance manager)

This nexus appears to be conflicting in the official accounts. The workings of the official accounts in practice, and the nature of any conflict, are unclear at this stage. Further investigation of this phenomenon will ensue.

Interviewer: 'In your opinion, what are some of issue for future paramedic practice in the context of managing mental illness?'

Participant: 'I think for ambulance in the future, we need to able to have a high diagnostic sieve level for our officers, the ability to be able to differentiate causes of disturbed and abnormal behaviour, which is the manifestation that we see that obviously triggers as to why someone calls the ambulance. I think in the past if someone's behaviour was behaviour in a bizarre or abnormal way, it was the same process-they were simply dragged off to hospital. If they couldn't be dragged off to hospital the police were called and they were taken into police custody. So there wasn't too many options in terms of how they were managed...' (Excerpt of interview with participant 2 - senior ambulance education official) 
At interview, the issue of interpretation of the term 'belief' as intended by the Mental Health Act 2000 in contrast to the 'judgment' mandated by official clinical practice guidelines was explored.

Interviewer: 'What is your sense interpretation of the term 'belief' in the Mental Health Act and its workings? How might be viewed or interpreted by paramedics, their 'belief; someone is mentally ill? Does that imply judgement, does it imply level of assessment or that somebody just has a hunch of it?'

Participant 5: 'OK, people don't make an informed diagnosis for judgment. In other words I don't believe that people are doing anything other than operating on an extinct or a hunch. Yeah ok a hunch. In the absence of overt information this bloke might have suicidal assessment instrument.' (Excerpt of interview with participant 5 - ambulance counsellor)

These and other themes will be examined and explored in detail in the continuing study.

\section{Significance and Future Considerations}

It appears from this data that tensions between and across official accounts appear to dominate how policy and practice is mandated, and that a variety of factors other that those related directly to education influence paramedic judgment and decision-making. This study suggests that the changing role of the paramedic in assessing and managing mental illness in a rapidly changing pre-hospital care environment has not been comprehensively examined. This appears to have contributed to role confusion in the face of competing and conflicting official accounts, with insufficiencies in the preparation for practice. The participants explicated a need for additional skills and training, specifically a tool to better guide their practice-also known as prescriptive accounts of judgment and decision-making. The sufficiency of programs then for ensuring quality care and accountability in the field is heavily dependent on the systematic examination of practice in the pursuit evidence-based practice. The data suggests that paramedics themselves have identified a gap in their knowledge and skills. Improvement in clinical practice and patient care outcomes is more than just about providing training - it is about the systematic characterising and evidencing existing practice that make known the very issues that guide and mandate such practice in the field. It is also about recognising the evolving role of paramedics in the field and characterising contextual variables and interactions that impact on the paramedic's preparedness and ability to provide quality patient care. Although not intended to be generalisable across populations, the purposeful, systemic, and structured selection of participants; application of a comprehensive and integrated data collection methods; structured data analysis; and rich, thick descriptions of the ecologies under study should provide for some insight into the complexity of paramedic JDM, ultimately aiming to improve the quality of care provided to individuals suffering from a mental illness by improving pre-hospital recognition and management of these conditions, and the preparedness of paramedics to do so.

Preliminary thematic considerations reported here provide an introductory look at the characteristics of paramedic JDM of mental illness. The continuing study will pursue greater exploration and examination of these themes and their relevance to paramedic JDM in an attempt to provide a rich and thick description of the nature and ecology of paramedic JDM of mental health and illness. It is anticipated that additional components of the continuing study 
will provide greater insight and understanding into these and other challenges of paramedic judgment, decision-making and practice in the pre-hospital context. 


\section{References}

1.Shaban RZ: Mental health assessments in paramedic practice: A warrant for research and inquiry into accounts of paramedic clinical judgment and decision-making. Journal of Emergency Primary Health Care 2004, 2(3-4).

2.Shaban RZ: Mental health assessments in paramedic practice: case analysis of the constructs of knowledge and judgment. In: Doing the public good: Positioning education research: 28 November - 2 December, 2004 2004; Melbourne, Australia: The Australian Association for Research in Education; 2004: 234.

3.Shaban RZ: Theories of judgment and decision-making: A review of the theoretical literature. Journal of Emergency Primary Health Care 2005, 3(TBA).

4.Shaban RZ: Clinical judgment and assessment tools for mental health and mental status examination: A review of the literature. Pre-hospital Emergency Care 2005, TBA(TBA):TBA.

5.Shaban RZ: Accounting for assessments of mental illness in paramedic practice: A new theoretical framework. Journal of Emergency Primary Health Care 2005, TBA(TBA).

6.Freebody P: Qualitative research in education: interaction and practice, 1st edn. London: SAGE Publications; 2004.

7.Silverman D (ed.): Qualitative research: Theory, method and practice. SAGE Publications: London, UK; 2003.

8.Silverman D: Interpreting Qualitative Data, 2nd edn. London: SAGE Publications; 2001.

9.Baker C: Membership categorisation and interview accounts. In: Qualitative research: theory, method and practice. Edited by Silverman D. London: SAGE Publications; 2003.

10.Fontaine KL, Fletcher JS: Mental health nursing. Sydney: Addison Wesley; 1999.

11.Wand T, Happell B: The mental health nurse: contributing to improved outcomes for patients in the emergency department. Accident and Emergency Nursing 2001, 9:166-176.

12.Green G: Emergency psychiatric assessments: do outcomes match priorities? International Journal of Health Quality Assurance 1999, 12(7):309-313.

13.Reinish LW, Ciccone R: Involuntary hospitalization and police referrals to a psychiatric emergency department. Bulletin of the American Academy of Psychiatry and Law 1995, 23(2):289-298.

14.Lamb HR, Shaner R, Elliott DM, DeCuir WJ, Foltz JT: Outcome for psychiatric emergency patients seen by and outreach police mental health team. Psychiatric Services 1995, 46(12):1276-1271.

15.Dhossche DM, Ghani SO: Who brings patients to the psychiatric emergency room? Psychosocial and psychiatric correlates. General Hospital Psychiatry 1998, 20:235-240.

16.Thompson C, Dowding $\mathrm{D}$ : Clinical decision making and judgement in nursing. London: Churchill Livingstone; 2002.

17.Commonwealth Department of Health and Aged Care: The National Mental Health Report 2000: Changes in Australia's Mental Health Services under the First National Mental Health Plan of the National Mental Health Strategy 1993-1998. Canberra: Australian Government; 2000. 
Other papers in this series:

Paper One - Mental health and mental illness in paramedic practice: A warrant for research and inquiry into accounts of paramedic clinical judgment and decision-making. http://www.jephc.com/full_article.cfm?content_id=170

Paper Two - Theories of clinical judgment and decision-making: A review of the theoretical literature.

http://www.jephc.com/full_article.cfm?content_id=192

Paper Three - Accounting for assessments of mental illness in paramedic practice: A new theoretical framework.

http://www.jephc.com/full article.cfm?content id=263

\section{Acknowledgments}

The author would like to acknowledge and thank Associate Professor Claire Wyatt-Smith and Professor Joy Cumming for their supervision and support, and Mr Jason Emmett for his editorial review of this manuscript.

\section{Author Disclosure}

The author has no financial, personal or honorary affiliations with any commercial organization directly involved or discussed in this study.

This Article was peer reviewed for the Journal of Emergency Primary Health Care Vol.3, Issue 4, 2005 